\title{
Beyond the mask of deference: exploring the relationship between ruptures and transference in a single-case study
}

\author{
Francesca Locati, Pietro De Carli, Emanuele Tarasconi, Margherita Lang, Laura Parolin \\ Department of Psychology, University of Milano-Bicocca, Milan, Italy
}

\begin{abstract}
The relationship between transference and therapeutic alliance has been long discussed. It is only recently, however, that empirical evidence has provided support for a tight correspondence between several transference dimensions and rupture and resolution processes. In the present single-case study, we used alliance ruptures as a key dimension to understand patient's transference dynamics. This was achieved in a particular form of patient's behavior, i.e., patient's deference and acquiescent behavior, which describes a significant submission to assertions, skills, judgments and point of views of another person. Therapeutic process was measured by means of the Rupture Resolution Rating Scale, the Core Conflictual Relationship Theme and the Defense Mechanism Rating Scales, whereas therapeutic outcome was measured by means of the Shedler-Westen Assessment Procedure-200. Results of sequential analysis yielded a significant correspondence between rupture markers, characterized by avoidance and shifting of session's topic, and patient's narrations. Furthermore, a systematic correspondence between alliance ruptures and patient's avoidant functioning, which emerged both in transference relationship and in the quality of the defense structure, was found. Together, these findings indicate that patient's deference inhibits the expression of relational themes, with ruptures in alliance that seem to be supported by a strong defensive structure. In particular, patient's avoidance played a double role in the treatment. On the one hand, avoidance was the main characteristic of her transference structure, based on extreme intellectualization and emotional closure. On the other hand, it contributed to create an impasse in the treatment, based on a withdrawal ruptures model and on obsessive level defences.
\end{abstract}

Key words: Therapeutic alliance; Transference; Deferent behavior; Single-case study.

Correspondence: Francesca Locati, Department of Psychology, University of Milano-Bicocca, Piazza dell'Ateneo Nuovo 1, Edificio U6, 20126 Milan, Italy.

E-mail: francesca.locati@unimib.it

Contributions: FL developed the study concept; ET performed data collection and scoring; FL and PDC performed the data analysis and interpretation under the supervision of LP; FL drafted the manuscript, and ML and LP provided critical revisions. All authors contributed to the study design and approved the final version of the manuscript for submission.

Conflict of interest: the authors declare no potential conflict of interest.

Citation: Locati, F., De Carli, P., Tarasconi, E., Lang, M., \& Parolin, L. (2016). Beyond the mask of deference: exploring the relationship between ruptures and transference in a single-case study. Research in Psychotherapy: Psychopathology, Process and Outcome, 19(2), 89-101. doi: 10.4081/ripppo.2016.212

Received for publication: 15 May 2016

Revision received: 1 October 2016.

Accepted for publication: 1 October 2016.

This work is licensed under a Creative Commons Attribution NonCommercial 4.0 License (CC BY-NC 4.0).

CCopyright F. Locati et al., 2016

Licensee PAGEPress, Italy

Research in Psychotherapy:

Psychopathology, Process and Outcome 2016; 19:89-101

doi:10.4081/ripppo.2016.212

\section{Introduction}

Since the first theorization, one of the most prolific issues about therapeutic alliance has concerned its relationship with transference. After Freud's work The Dynamics of Transference (1912), psychoanalytic theorists have been describing the alliance as independent from the transference, although they also conceived some degrees of overlap, at least at the empirical level. For instance, Sterba (1934) and Bibring (1937), referred to alliance as a scission of the Ego, while others, like Nunberg (1928), described it as a relationship based on the same libido roots of the transference and motivated by narcissistic drives. Critically, until the work by Zetzel (1956) and the other Ego-psychology authors, psychoanalytic models of therapy rejected the alliance as the cornerstone of the treatment (Freud, 1912; Lacan, 1955; Greenacre, 1968; Brenner, 1979; Curtis, 1979). In contrast with them, Zetzel (1956) described the psychoanalytic process as completely based on the cure and the maintenance of a stable and strong therapeutic alliance. Similarly, Greenson (1967) focused on the most practical characteristic of therapeutic alliance, referred to as the working alliance. For all the Ego psychologists, indeed, a necessary condition for the establishment of an enduring alliance was a high level of Ego maturity, essential also for the beginning of a rational and desexualized relationship (Greenson, 1967).

Thanks to the advent of empirical research in psy- 
chotherapy, clinicians and researchers created new methods to explore transference, as well as its association with alliance construct (Levy \& Scala, 2012). The new emphasis conveyed by empirical research, nevertheless, did not clarify the controversial relationship between these two constructs. Meissner, in 1996, warned against the difficulty of studying these two constructs, because once they are operationalized, they become partially overlapping. The relational turn in psychodynamic theory and the new pantheoretical view of some cornerstones (Bordin, 1975) produced new measure tools aimed at describing and evaluating alliance and transference and a more specific reconceptualization of these two constructs. Freud (1905) described transference as the repetition of an old objectrelationship, in which feelings and impulses of an old significant object are transferred on the analyst. This theory is not based on the real relationship in therapeutic dyad, but rather on unconscious and regressive distortion. The new reconceptualization made by recent relational theories in psychoanalysis describes transference as an interactive communication (Lingiardi, 2002), in which the symmetry between patient and therapist represents the real engine of treatment.

Following these intuitions, Safran and Muran (1996) suggested that there might be stable associations between several transference dimensions and alliance rupture and resolution processes, with ruptures defined as critical points of deterioration in the patient-therapist relationship. If not promptly recognized and resolved, indeed, ruptures can develop an impasse or a premature ending of treatment (Safran, Muran, Samstag \& Winston, 2005). Ruptures involve episodes in which both therapist and patient become implicated in unhelpful and negative reactions (Safran \& Muran, 2006). In the latest empirical model of their theory about ruptures and resolution, Safran and Muran (2000) highlight the important role played by transference in the comprehension of the relational meaning of patient's ruptures. For instance, depending on the nature of transference, patient can show aggressiveness or sad feelings, denying his/her anger or vulnerability and using neurotic defence mechanism, such as rationalization or denial (Safran \& Greenberg, 1987; Safran, Muran \& Samstag, 1994; Safran \& Muran, 1996). Notably, under a relational approach, ruptures of the alliance between patient and therapist can be used as a key to understand patient's transference dynamics and relational behavior patterns. Accordingly, conflicts in therapeutic dyad are conceived as central to the exploration of patient's unconscious life. Similarly, repairing ruptures is often related to positive outcome in treatment (Safran, Muran \& EubanksCarter, 2011). Oppositely, if the rupture remains unresolved, this may lead to patient's dropout or to an impasse in treatment (Henry, Schacht \& Strupp, 1986). In order to clarify the relationship between ruptures in the alliance and patient's transference, Safran and Muran found an empirical association between episodes of rupture in the alliance codified on verbatim transcriptions, by means of their Rupture Resolution Rating Scale (3RS; EubanksCarter, Muran \& Safran, 2015) and transference material, inferred from patient's Core Conflictual Relationship Theme (CCRT; Luborsky \& Crits-Cristoph, 1998). In their model, patient's transference can clarify the unconscious relational meaning of specific episodes of rupture. If therapeutic alliance is a necessary condition for a good outcome, resolution of its ruptures may play an important role in treatment, facilitating the expression of negative feelings about treatment or therapist. Because therapeutic alliance is influenced by transference, patient's relational behavior represents a critical juncture for theoretical, clinical and research attention (Figure 1).

The aim of the present study, therefore, is to examine a particular form of patient's behavior, i.e., the deference and acquiescent behavior, by exploring patient's therapeutic alliance, transference dynamics and defense mechanisms.

Deference describes a significant submission to assertions, skills, judgments and point of views of another person. This behavior plays a very important role in the dynamics of psychotherapy, because the asymmetry of power and competence between therapist and patient can potentiate patient's deference. Nevertheless, this particular form of relationship has not received enough attention in psychotherapy literature (Rennie, 1994). Until the end of the Eighties, the only theoretical source about the deference were the philosophical and sociological works of Goffmann (1961) and Foucault (1963) about people's submission to the authoritarian and despotic schemas in treatment centers, and the works of symbolic interactionists (Mead, 1934). On the contrary, researcher's attention was mainly drawn to constructs commonly related to improvements in psychotherapy, like collaboration, resistance, transference and therapeutic alliance. Therefore, the first studies about the deferential behavior analyzed only the relationship between this construct and other clinical phenomenon. Inherently related to the withdrawal model of rupture in the Safran and Muran theory, the deferential behavior has been explored by Rennie (1994) in a quantitative study using factor analysis. Rennie (1994) extracted five latent factors beyond the patient's deferential behavior: fear of hurting the therapist, need to support his/her hypothesis, implicit acceptance of his/her limits, fear to excessively criticise him/her and the fear to appear ungrateful, respectively. Results showed that this particular behavior might be very dangerous for the stability of therapeutic alliance because an overlap with the patient's habitual relational patterns leads the patient to an inability in expressing her/his discomfort and her/his awkwardness during the sessions (Rennie, 1994). In such case, this feeling may therefore induce the patient to interrupt the therapy without any verbalization of the rupture or to a non-verbalized passivity, which can obstruct the therapy process. Furthermore, from their point of view, therapists seemed to be blind to the nonverbal signals of a deferen- 
tial behavior supported by withdrawal ruptures (Rennie, 1994). This is also in line with Hill and colleagues' study (Hill, Nutt-Williams, Heaton, Thompson \& Rhodes, 1996) on the analysis of the therapist's memories of the ruptures, which led the patient to interrupt the treatment. Taken together, these results support the idea that the deferential behavior of the patient, the non-observance of the withdrawal ruptures' markers and the theoretical rigidity of the therapists can all lead to an illusory type of alliance that is not followed by a significant improvement of the patient and that can be, therefore, very dangerous for the therapy process. In order to better investigate this possibility, in the present study we explored the patient's defensive structure. In fact, withdrawal ruptures in a deferential patient may indicate deterioration in the therapeutic relationship, which can be accompanied by a form of resistance to treatment. The activation of defence mechanisms during the therapy is therefore strictly connected to transference-countertransference dynamics, but also to the real relationship with the therapist (Safran, Muran \& Shaker, 2014). In this sense, withdrawal ruptures may represent critical points in therapy. At the basis of our hypothesis, withdrawal ruptures may be strictly connected to the resistance that emerges from the intersubjective matrix of the therapeutic dyad. As a conse- quence, a deeper comprehension of the defensive functioning of the patient can inform about the relational and bi-personal meaning of ruptures in the alliance. Deference may represent, indeed, a very insidious problem for researchers and clinicians because it can negatively influence the inter-subjective dynamic of the therapy (Colli \& Lingiardi, 2009).

On these grounds, the present study aims to explore the dynamics of deferential behavior in relationship with other clinically relevant constructs (i.e., transference, defense mechanisms and alliance ruptures). This was done in a single-case study of a patient who, during the treatment, showed a very strong and inflexible deferential approach to the therapist.

\section{Materials and Methods}

\section{Case description}

Patient. Sara is a 33 year-old lawyer. She came to therapy complaining about anxiety symptoms, insomnia and fear of losing control. The psychological assessment, composed of Wechsler Adult Intelligence Scale-Revised (Wechsler, 1981) and Rorschach Test (Exner, 1993) revealed that Sara has a high cognitive functioning level and

\section{ALLIANCE RUPTURES AND TRANFERENCE}

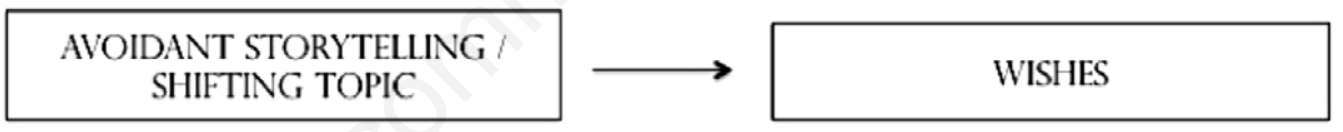

\section{ALLIANCE RUPTURES AND DEFENCE MECHANISM}

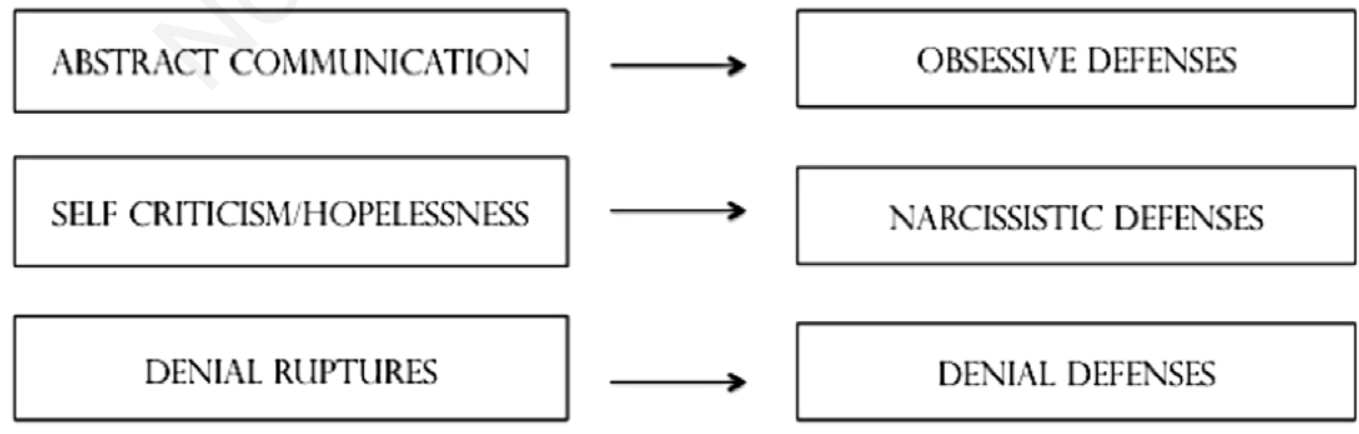

TRANFERENCE AND DEFENSE MECHANISM

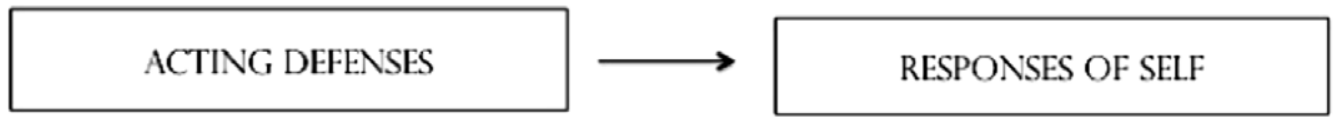

Figure 1. Alliance ruptures, transference and defence mechanisms. 
a rigid way of thinking. This functioning is characterized by hypervigilance and emotional constriction. The clinician believed that Sara's emotions are often replaced by an anxiety status. Sara's father suddenly died when she was five years old: the clinician supposed that this traumatic event could play an important role in her symptomatic structure. Sara was diagnosed with a generalized anxiety disorder (American Psychiatric Association, 2013) and a neurotic personality organization with a rumination attitude. Before beginning of the treatment, Sara gave her consent to audio-record the sessions and to use them for research purposes, prior to de-identification of all sensitive information.

Therapist. Sara is currently undergoing a weekly psychodynamic therapy with an expert clinician. Dr. L. is a 65 year-old female clinical psychotherapist with 35 years of clinical experience. She identifies herself as psychodynamic-oriented therapist.

\section{Measures}

\section{Process measure}

The 3RS (Eubanks-Carter et al., 2015) is used to evaluate and to quantify, from an external point of view, the ruptures or the moments of impasse in therapeutic alliance. 3RS has demonstrated high level of inter-rater reliability (intraclass correlation=.73-.96; Coutinho, Ribeiro, Sousa \& Safran, 2014); the evaluation is made by external observers on video-recorded sessions or verbatim transcriptions.

Contents of the discourse, verbal language style and emotion intensity are important parameters in rupture's evaluation. This instrument identifies two types of rupture: the withdrawal (WD) and the confrontation (C). Withdrawal ruptures indicate that the patient avoids the therapist's questions or denies important aspects of his/her own experience (e.g., by appearing deferential and appeasing). During $\mathrm{C}$ ruptures, the patient seems to go against the therapist, expressing hostility or dissatisfaction in a non-collaborative manner (e.g., by complaining about the therapist) or trying to manipulate the therapist (e.g., by asking questions to the therapist).

The CCRT (Luborsky \& Crits-Christoph, 1998) is used to find the conflictual core of the relational functioning of the patient from his verbally expressed narratives. The CCRT is among the best validated and most psychometrically sophisticated clinician-based method for assessing transference patterns (Luborsky \& Diguer, 1998; Barber, Luborsky, Crits-Christoph \& Diguer, 1998; Luborsky, Crits-Christoph \& Alexander, 1990). It is based on the identification of specific narrative unities in sessions' verbatim transcripts. These unities include the explicit description of relational episodes (RE) in which patient expresses his wishes $(\mathrm{W})$, the response of others (RO) and his/her reactions to them (responses of self, RS). The division between these three standard categories of CCRT reflects the need to obtain comparable data from different relational areas of patient's functioning. Primary data used to identify patient's CCRT are narrative episodes. These episodes usually concern important relationships (i.e., with parents, friends, superiors, partners or with the therapist) that are discussed during the psychotherapy sessions. The judge codes RE's on a verbatim transcription, identifying the moments when the narratives of the patients reflect his/her usual relational behavior patterns. Then, the judge identifies the three components: i) the patient's main $\mathrm{W}$ or needs, ii) the RO, and iii) the RS. After this scoring, the most frequent items of the three components are combined together to constitute the patient's CCRT. The CCRT is a very flexible instrument, adaptable to different clinical contexts.

The Defense Mechanism Rating Scales (DMRS; Perry, 1990; Perry \& Henry, 2004) is used to assess defense mechanisms. The DMRS defenses are comparable to those listed in the Diagnostic and Statistical Manual of Mental Disorders (DSM)-fourth revision (IV) (American Psychiatric Association, 1994). The instrument describes 30 defense mechanisms assigned to seven hierarchical levels of defensive functioning: high adaptive (mature), obsessional, other neurotic, minor image-distorting, disavowal, major image-distorting, and action defenses. Each of this level includes 3-to-8 individual defenses. Many studies have supported DRMS's validity and reliability (Guldberg, Hoglend \& Perry, 1993; Perry, 2001; Skodol \& Perry, 1993).

\section{Outcome measure}

The Shedler-Westen Assesment Procedure (SWAP)200 (Westen \& Shedler, 1999) is a Q-sort instrument designed to quantify clinical judgment of personality pathology, with large evidence of strong reliability (Westen \& Muderrisoglu, 2003; Marin-Avellan, McGauley, Campbell \& Fonagy, 2005; Westen \& Shedler, 2007; Blagov, Bi, Shedler \& Western, 2012). The set of 200 personality-descriptive statements is ranked into eight categories, following a fixed distribution, by a clinician with a good knowledge of the patient. The resulted ordering of the items is then compared with diagnostic prototypes representing each DSM axis II personality disorders to ascertain the degree of match. The resulting SWAP descriptions were averaged to arrive at a single, aggregate prototype representing the core clinical consensus on the features of each personality disorder (Westen \& Shedler, 1999). Overall, these diagnostic prototypes were found to be different from DSM criteria.

\section{Hypothesis}

The aim of this single-case study is to explore and understand patient's deferential behavior in the therapeutic process, by investigating the alliance ruptures and their relationship with transference and defensive functioning.

First, we hypothesize to observe a deferential behavior in Sara's functioning profile, by exploring the more fre- 
quent patterns of components of the CCRT, of alliance ruptures and of defense mechanisms markers, during the therapy. In particular, we expect RE (i.e., CCRT) of W to be characterized by social and work approval, of RO to be characterized by refusal and disapproval, and of RS to be characterized by idealization and devaluation. These hypotheses are in line with the literature on deferential approach to relationships, which would be characterized by the avoidance of direct confrontation (Brown \& Levinson, 1987). These dynamics emerge from an interpersonal matrix in which power asymmetry in relationship leads the deferential individual to conceptualize his/her opinions as not important or negligible and his/her interlocutor as potentially rejecting (Rennie, 1994). In terms of alliance ruptures, since the deferential behavior leads the patient to avoid the conflict with therapist's assertions (Rhodes, Hill, Thompson, Elliott 1994), we expect WD as the most frequent rupture and, in particular, the deferential and appeasing rupture and the minimal communication. With respect to the defensive profile, we expect a high frequency of obsessive and denial defense mechanisms, which would protect the patient from the anxiety driven by the intimate therapeutic relationship (Rennie, 1994; Perry, 1990).

Second, we hypothesize to find an association between Sara's transference pattern, alliance rupture markers and defense mechanism.

We expect a relationship between alliance ruptures (i.e., 3RS) and relational episodes (i.e., CCRT). More specifically, we expect an association between rupture markers characterized by a deferential approach, such as avoidant storytelling/shifting topic (AS/ST), deferential and appeasing rupture, and specific components of the patient's CCRT, especially W. In fact, in a typical deferential patient, WD ruptures may inhibit specific components of the transference, in particular patient's wishes and needs (Hill et al., 1996). The association between ruptures and transference may, therefore, unveil an important dynamic that may in turn help understand the deferential approach to the treatment.

We also hypothesize that the patient's tendency to isolate affects should be linked to avoidance in the relationship with the therapist. More specifically, we hypothesize that either ruptures in the alliance or relational episodes should be associated to a defensive structure based on intellectualization, isolation, denial and rationalization. With respect to alliance and defense mechanisms, we first hypothesize an association between withdrawal ruptures and intellectualization, isolation, denial and rationalization defenses. With respect to the relationship between transference and defense mechanisms, we then expect patient's defensive structure (i.e., characterized by neurotic, obsessive and denial defenses) to obstruct the narration of elaborated RE, in particular those regarding the RS.

Third, and finally, we hypothesize that the deferential behavior would lead to an impasse in the treatment and to obstacle a successful therapy outcome. Following the conceptualization of deference by Rhodes and colleagues (1994), therapist's difficulties in recognizing the negative covert signals of the patient would lead to an impasse in the treatment.

\section{Procedures}

In the present study we used three different process measures that were applied on 36 transcripts of the sessions. Transcripts were randomly selected among 63 sessions, covering equally the temporal phases (i.e., initial, central, and last phase) of therapy.

All the 36 sessions were audio-reordered and then transcribed in verbatim transcript. The transcriptions were coded with 3RS, CCRT and DMRS, by two experienced judges who blindly rated all transcripts. The two raters are psychologists well-trained and supervised in all the measures (including SWAP-200) by an expert. They coded all transcripts ignoring the sequence of sessions and without being aware about the hypothesis of the research.

The first step of CCRT administration consists in the identification of the RE. The two raters identified the same number of episodes in each session.

The scores showed a good inter-rated reliability between them (mean Cohen's K for 3RS $=.75$, for $\mathrm{CCRT}=.84$ and for DMRS $=.78$ ). Similarly, SWAP-200, which was applied only on the first and last five sessions of the therapy, reached a good inter-rated reliability (SWAP-200=.72).

According to the first hypothesis, in order to obtain a general profile of patient's functioning, we analyzed qualitatively the more frequent items emerging from descriptive analyses of CCRT, 3RS and DMRS measures. In CCRT, we also considered the pervasiveness of each item in the relational episodes.

The second group of hypotheses was tested by means of a multievent sequential analysis performed with the Generalized Sequential Querier software (GSEQ 5.1; Bakeman \& Quera, 2011). Sequential analysis determines the probability of occurrence of a given behavior together with the occurrence of a target behavior (see for applicative examples in the field of psychotherapy research, Russell \& Trull, 1986; Safran et al., 1994). Hence, no causality effect is implied in sequential analysis. For the hypothesis $2 a$, in order to investigate the association between alliance ruptures and transference pattern, we analyzed the co-occurrence (i.e., sequential analyses) of 3RS items and CCRT components. For the hypothesis $2 b$, in order to investigate the relationship between alliance ruptures and patient's defensive functioning, we first analyzed the co-occurrences of specific 3RS and DMRS markers; then, in order to investigate the relationship between defensive structure and relational episodes, we also analyzed the co-occurrence of DMRS markers and CCRT components.

Finally, according to the third hypothesis, in order to identify and investigate how patient's deferential approach influenced the progression of the treatment, we 
compared patient's SWAP profile evaluations in the first and in the last five sessions of therapy. To obtain a profile consistent with the DSM diagnosis, SWAP PD scores were used. In particular, we used the reliable change index (RCI) (Jacobson \& Truax, 1991) to test if the patient showed a clinically significant change from the first to the second evaluation on the SWAP-200 scores and the personality health index (PHI).

\section{Results}

First, the descriptive analysis of CCRT showed a low number of RE for session [mean $(\mathrm{M})=5.7$, standard deviation $(\mathrm{SD})=1.87]$. The descriptive analysis of CCRT is expressed in standard categories: the $\mathrm{W}$ component, the RO component and the RS component. For the $\mathrm{W}$ component, the most frequent categories that emerged were: the wish to be close to others (W11 $12.8 \%$; N=25), the need to achieve (W22 $=12.3 \% ; \mathrm{N}=24$ ), and the need to feel comfortable (W31 $=15.9 \% ; \mathrm{N}=21$ ). For the $\mathrm{RO}$ component, the most frequent categories that emerged were: the distance from the others ( $\mathrm{RO} 12=9.2 \% ; \mathrm{N}=18)$, acceptance of the others $(\mathrm{RO} 3=9.2 \% ; \quad \mathrm{N}=18)$, rejection of others (RO4 $=8,7 \% ; \mathrm{N}=17$ ), and unhelpfulness of others (RO14=8.7\%; N=17). Finally, for the RS component, the most frequent categories that emerged were: expression of anxiety states (RS27 $=21.6 \%$; $\mathrm{N}=42$ ), feelings of uncertainty (RS19 $=20.1 \% ; \mathrm{N}=39$ ), and reaction of guilt trip (RS25=16.4\%; $\mathrm{N}=32$ ). The aforementioned standard categories determined the $\mathrm{W}$, the $\mathrm{RO}$ and the RS components of Sara's CCRT.

The descriptive analysis of 3RS showed a large stereotypical and inflexible use of the minimal response rupture $(\mathrm{N}=451)$ and of the deferential and acquiescent ruptures $(\mathrm{N}=425)$. Regarding other rupture markers, only the affect split rupture (AS) exceeded 50 verbal unities $(\mathrm{N}=55)$. Finally, the descriptive analysis of DMRS showed a large use of obsessive defenses, such as isolation $(\mathrm{N}=113)$ and reaction formation $(\mathrm{N}=60)$, and neurotic defenses, such as repression $(\mathrm{N}=109)$ and displacement $(\mathrm{N}=84)$. With respect to the narcissistic defenses, devaluation $(\mathrm{N}=100)$ was the most activated defense mechanism. Mature defenses of auto-observation $(\mathrm{N}=78)$ and humour $(\mathrm{N}=41)$ were also frequently activated during the therapy.

Successively, for the hypothesis 2a, results of the cooccurrence analysis of 3RS items and CCRT components showed a significant co-occurrence between AS/ST from 3RS and W from CCRT. AS/ST also showed a negative co-occurrence with the RO categories $(\mathrm{P}<.05)$ (Table 1).

Critically, for the hypothesis $2 \mathrm{~b}$, the co-occurrence analysis of DMRS and 3RS items showed that the most frequent rupture marker, i.e., the minimal response rupture, co-occurred negatively only with obsessive defenses $(\mathrm{P}<.05)$. Furthermore, the abstract communication rupture marker co-occurred significantly with obsessive defenses $(\mathrm{P}<.01)$, whereas the auto-criticism rupture co-occurred sig- nificantly with narcissistic defenses $(\mathrm{P}<.01)$. Lastly, analyses showed a significant co-occurrence between denial rupture marker and denial defenses $(\mathrm{P}<.01)$ (Table 2). The co-occurrence analysis between CCRT items and DMRS components revealed a significant co-occurrence between the narration $\mathrm{RO}$ and acting defenses $(\mathrm{P}<.01)$. This type of narratives also showed a negative co-occurrence with mature and high defenses $(\mathrm{P}<.05)$ (Table 3 ).

Finally, we used the SWAP-200 to analyze the progression of the treatment and how patient's deferential behaviors influenced it. Results did not show a significant change on the RCI between pre- and post-assessment (Figure 2). On the contrary, the analysis of the PHI indicated a slow and gradual improvement, especially for the reality exam index $(+25 \%)$ and the identity integration index $(+23 \%)$ (Table 4$)$.

\section{Discussion}

The present study used a single-case research to explore the association between therapeutic alliance and

Table 1. Co-occurrence analysis of Rupture Resolution Rating Scale and Core Conflictual Relationship Theme.

\begin{tabular}{|c|c|c|c|c|}
\hline 3RS marker & $\begin{array}{l}\text { CCRT } \\
\text { component }\end{array}$ & $\mathbf{N}$ & $\begin{array}{c}\text { Adjusted } \\
\text { residual }\end{array}$ & $\mathbf{P}$ \\
\hline \multicolumn{5}{|c|}{ Minimal response } \\
\hline & W & 13 & -0.32 & $\sim .75$ \\
\hline & RO & 6 & 0.45 & $\sim .65$ \\
\hline & RS & 9 & -0.03 & $\sim .98$ \\
\hline \multicolumn{5}{|c|}{ Abstract communication } \\
\hline & W & 6 & -0.76 & $\sim .45$ \\
\hline & RO & 1 & -1.29 & $\sim .20$ \\
\hline & RS & 8 & 1.88 & $\sim .06$ \\
\hline \multicolumn{5}{|l|}{$\mathrm{AS} / \mathrm{ST}$} \\
\hline & W & 13 & 2.17 & $\sim .03$ \\
\hline & RO & 3 & -0.24 & $\sim .81$ \\
\hline & RS & 2 & -2.12 & $\sim .03$ \\
\hline \multicolumn{5}{|l|}{ Affect spli } \\
\hline & W & 4 & -0.60 & $\sim .55$ \\
\hline & RO & 2 & 0.12 & $\sim .91$ \\
\hline & $\mathrm{RS}$ & 4 & 0.54 & $\sim .59$ \\
\hline \multicolumn{5}{|l|}{ Denial } \\
\hline & W & 0 & 0.00 & $\sim 1.00$ \\
\hline & RO & 0 & 0.00 & $\sim 1.00$ \\
\hline & RS & 0 & 0.00 & $\sim 1.00$ \\
\hline \multicolumn{5}{|c|}{ Self-criticism/hopelessness } \\
\hline & W & 0 & -0.99 & $\sim .32$ \\
\hline & RO & 0 & -0.48 & $\sim .63$ \\
\hline & $\mathrm{RS}$ & 1 & 1.45 & $\sim .15$ \\
\hline \multicolumn{5}{|c|}{ Deferential and appeasing } \\
\hline & $\mathrm{W}$ & 14 & -0.31 & .76 \\
\hline & RO & 7 & 0.79 & .43 \\
\hline & RS & 9 & -0.33 & .74 \\
\hline
\end{tabular}

CCRT, Core Conflictual Relationship Theme; 3RS, Rupture Resolution Rating Scale; W, wishes; RO, response of others; RS, response of self; AS/ST, avoidance storytelling/shifting topic. $\sim<$ P value does not meet the condition of normality assumption. 
Table 2. Co-occurrence analysis of Rupture Resolution Rating Scale and Defense Mechanism Rating Scale.

\begin{tabular}{|c|c|c|c|c|}
\hline 3RS marker & $\begin{array}{l}\text { DMRS } \\
\text { level }\end{array}$ & $\mathbf{N}$ & $\begin{array}{l}\text { Adjusted } \\
\text { residual }\end{array}$ & $\mathbf{P}$ \\
\hline \multicolumn{5}{|c|}{ Minimal response } \\
\hline & Mature defenses & 8 & 1.29 & .20 \\
\hline & Obsessive defenses & 6 & -2.30 & .02 \\
\hline & Neurotic defenses & 10 & 1.06 & .29 \\
\hline & Narcissistic defenses & 3 & 0.00 & $\sim 1.00$ \\
\hline & Denial defenses & 2 & -0.13 & $\sim .90$ \\
\hline & Borderline defenses & 0 & 0.00 & $\sim 1.00$ \\
\hline & Acting defenses & 2 & 1.11 & $\sim .27$ \\
\hline \multicolumn{5}{|c|}{ Abstract communication } \\
\hline & Mature defenses & 6 & -1.45 & .15 \\
\hline & Obsessive defenses & 30 & 3.37 & $<.01$ \\
\hline & Neurotic defenses & 11 & -0.79 & .43 \\
\hline & Narcissistic defenses & 3 & -1.17 & $\sim .24$ \\
\hline & Denial defenses & 3 & -0.45 & $\sim .65$ \\
\hline & Borderline defenses & 0 & 0.00 & $\sim 1.00$ \\
\hline & Acting defenses & 0 & -1.57 & $\sim .12$ \\
\hline \multicolumn{5}{|l|}{$\mathrm{AS} / \mathrm{ST}$} \\
\hline & Mature defenses & 9 & 1.47 & .14 \\
\hline & Obsessive defenses & 11 & -0.70 & .48 \\
\hline & Neurotic defenses & 11 & $1-14$ & .25 \\
\hline & Narcissistic defenses & 2 & -0.83 & $\sim .41$ \\
\hline & Denial defenses & 1 & -1.02 & $\sim .31$ \\
\hline & Borderline defenses & 0 & 0.00 & $\sim 1.00$ \\
\hline & Acting defenses & 0 & -1.18 & $\sim .24$ \\
\hline \multicolumn{5}{|l|}{ Affect split } \\
\hline & Mature defenses & 4 & 0.66 & $\sim .51$ \\
\hline & Obsessive defenses & 4 & -1.26 & $\sim .21$ \\
\hline & Neurotic defenses & 4 & -0.12 & $\sim .90$ \\
\hline & Narcissistic defenses & 3 & 1.17 & $\sim .24$ \\
\hline & Denial defenses & 1 & -0.19 & $\sim .85$ \\
\hline & Borderline defenses & 0 & 0.00 & $\sim 1.00$ \\
\hline & Acting defenses & 1 & 0.65 & $\sim .52$ \\
\hline \multicolumn{5}{|l|}{ Denial } \\
\hline & Mature defenses & 0 & -0.94 & $\sim .35$ \\
\hline & Obsessive defenses & 1 & -0.53 & $\sim .60$ \\
\hline & Neurotic defenses & 0 & -1.16 & $\sim .25$ \\
\hline & Narcissistic defenses & 0 & -0.66 & $\sim .51$ \\
\hline & Denial defenses & 3 & 5.39 & $\sim<.01$ \\
\hline & Borderline defenses & 0 & 0.00 & $\sim 1.00$ \\
\hline & Acting defenses & 0 & -0.37 & $\sim .71$ \\
\hline \multicolumn{5}{|c|}{ Self criticism/hopelessness } \\
\hline & Mature defenses & 0 & -1.43 & $\sim .15$ \\
\hline & Obsessive defenses & 4 & 0.43 & $\sim .67$ \\
\hline & Neurotic defenses & 0 & -1.76 & $\sim .08$ \\
\hline & Narcissistic defenses & 5 & 4.77 & $\sim<.01$ \\
\hline & Denial defenses & 0 & -0.84 & $\sim .40$ \\
\hline & Borderline defenses & 0 & 0.00 & $\sim 1.00$ \\
\hline & Acting defenses & 0 & -0.56 & $\sim .57$ \\
\hline \multicolumn{5}{|c|}{ Deferential and appeasing } \\
\hline & Mature defenses & 6 & -0.35 & .72 \\
\hline & Obsessive defenses & 14 & -0.11 & .91 \\
\hline & Neurotic defenses & 10 & 0.25 & .80 \\
\hline & Narcissistic defenses & 2 & -1.03 & .30 \\
\hline & Denial defenses & 3 & 0.25 & .81 \\
\hline & Borderline defenses & 0 & 0.00 & $\sim 1.00$ \\
\hline & Acting defenses & 3 & 1.83 & $\sim .07$ \\
\hline
\end{tabular}

DMRS, Defense Mechanism Rating Scale; 3RS, Rupture Resolution Rating Scale; AS/ST, avoidance storytelling/shifting topic. $\sim<$, P value does not meet the condition of normality assumption. transference in a patient with deference and acquiescent behavior. Overall, results showed that beyond an acquiescence facet, the patient concealed a resistance to the therapy. In particular, there was a systematic association between alliance ruptures and patient's avoidant functioning, which emerged both in transference relationship and in the quality of the defense structure.

First, frequency analyses on the CCRT components, along with a clinical interpretation of the verbatim transcripts (Table 5), showed a recognizable pattern in the expression of relational episodes. In fact, in Sara's narratives, the Self-dimension is frequently devaluated and felt as undeserving and shameful, while the representations of others are grave, severe and austere. Furthermore, her co-workers are often idealized and felt like right-life models, while her relatives are represented as boring, annoying or tedious.

Second, frequency analyses on the 3RS items, again along with a clinical interpretation of the verbatim transcripts (Table 5), helped us precisely identify Sara's typical way to interrupt the collaboration with the therapists. The modality of alliance ruptures was found to always be the withdrawal one. In fact alliance ruptures are always unexpressed, implicit and non-verbalized: Sara never puts herself directly in conflict with the therapist, and she never expresses her bad feelings about treatment's activities. This rupture model is strongly characterized by the minimal response rupture, i.e., the patient responds with short and clipped answers to open and exploratory questions, and by the deferential and appeasing rupture, i.e., the patient appears overly compliant and submits to the therapist in an excessively deferential manner. Notably, this stereotypical model of functioning during therapy is coherent with the literature on deferential behavior (Rennie, 1992) and on pathological rumination (Borkovec, Ray \& Stöber, 1998; Sassaroli \& Ruggiero, 2003).

Finally, frequency analyses on the DMRS items showed a more frequent use of neurotic, obsessive and mature defense mechanisms. These results, along with a clinical interpretation of the verbatim transcripts (Table 5), uncover a stereotypical and dysfunctional defensive structure. This defensive and relational model seems to reflect a grave narcissistic wound, which influences significantly the symptomatic dimension of pathological rumination. Moreover, this functioning may be responsible for patient's emotional detachment and may even activate her hypervigilant and intellectual behavior. Hence, it is likely that this relational structure leads the patient to avoid a real and rational alliance with the therapist and determines the construction of a pseudo-alliance.

These results, therefore, support our first hypothesis of a deferential behavior in Sara's functioning profile. In particular, these findings suggest that Sara always tries to avoid the conflict with the therapist. On the one hand, mature level defenses, like humor or auto-observation, are expressed to compensate the patient's resistant behaviors; 
on the other hand, immature, neurotical and obsessive defenses are expressed with the aim to avoid and isolate patient's negative feelings (Perry, 1990). Moreover, the narcissistic dimension of the patient seems to fluctuate persistently from the devaluation to the idealization pole depending on the episodes narrated in the treatment.

Notably, the relationship between the CCRT and the 3RS items was more comprehensively described by the sequential analysis. Indeed, results showed that W components of Sara's CCRT co-occurred significantly with a rupture marker characterized by avoidance and shifting of session's topic. In other words, patient's narrations do not express her real desires and needs, but her will to escape from the contact with the therapist. In particular, Sara's relational episodes are extremely schematic, unclear and incomplete: these narrative patterns are frequently expressed with the aim to avoid therapist's questions and to hide her emotive dimension. Therefore, passive avoidance and emotional closure seem to define the basis of Sara's transference.

The sequential analyses of DMRS and 3RS items are also coherent with the initial hypothesis that a deeper exploration of the defensive dimension may better clarify the functioning of episodes of rupture. One of Sara's most frequent rupture models, i.e., the abstract communication marker, co-occurred positively and significantly with obsessive defense mechanisms. This finding indicates that
Table 3. Co-occurrence analysis of Core Conflictual Relationship Theme and Defense Mechanism Rating Scale.

\begin{tabular}{|c|c|c|c|c|}
\hline CCRT component & $\begin{array}{l}\text { DMRS } \\
\text { marker }\end{array}$ & $\mathbf{N}$ & $\begin{array}{c}\text { Adjusted } \\
\text { residual }\end{array}$ & $\mathbf{P}$ \\
\hline \multicolumn{5}{|l|}{$\mathrm{W}$} \\
\hline & Mature defenses & 38 & 1.79 & .07 \\
\hline & Obsessive defenses & 28 & 0.08 & .94 \\
\hline & Neurotic defenses & 23 & 0.16 & .88 \\
\hline & Narcissistic defenses & 12 & -1.95 & .05 \\
\hline & Denial defenses & 11 & 1.26 & $\sim .21$ \\
\hline & Borderline defenses & 1 & -1.74 & $\sim .08$ \\
\hline & Acting defenses & 1 & -1.74 & $\sim .08$ \\
\hline \multicolumn{5}{|l|}{ RO } \\
\hline & Mature defenses & 10 & 0.26 & .79 \\
\hline & Obsessive defenses & 5 & -1.35 & .18 \\
\hline & Neurotic defenses & 8 & 0.70 & .48 \\
\hline & Narcissistic defenses & 7 & 1.15 & .25 \\
\hline & Denial defenses & 1 & -1.09 & $\sim .28$ \\
\hline & Borderline defenses & 2 & 1.41 & $\sim .16$ \\
\hline & Acting defenses & 0 & -1.02 & $\sim .31$ \\
\hline \multicolumn{5}{|l|}{$\mathrm{RS}$} \\
\hline & Mature defenses & 8 & -2.26 & .02 \\
\hline & Obsessive defenses & 15 & 1.07 & .28 \\
\hline & Neurotic defenses & 8 & -0.78 & .44 \\
\hline & Narcissistic defenses & 10 & 1.22 & .22 \\
\hline & Denial defenses & 3 & -0.50 & $\sim .62$ \\
\hline & Borderline defenses & 2 & 0.76 & $\sim .45$ \\
\hline & Acting defenses & 4 & 2.84 & $\sim<.01$ \\
\hline
\end{tabular}

DMRS, Defense Mechanism Rating Scale; CCRT, Core Conflictual Relationship Theme; $\mathrm{W}$, wishes; RO, response of others; RS, response of self. $\sim<$, P value does not meet the condition of normality assumption.

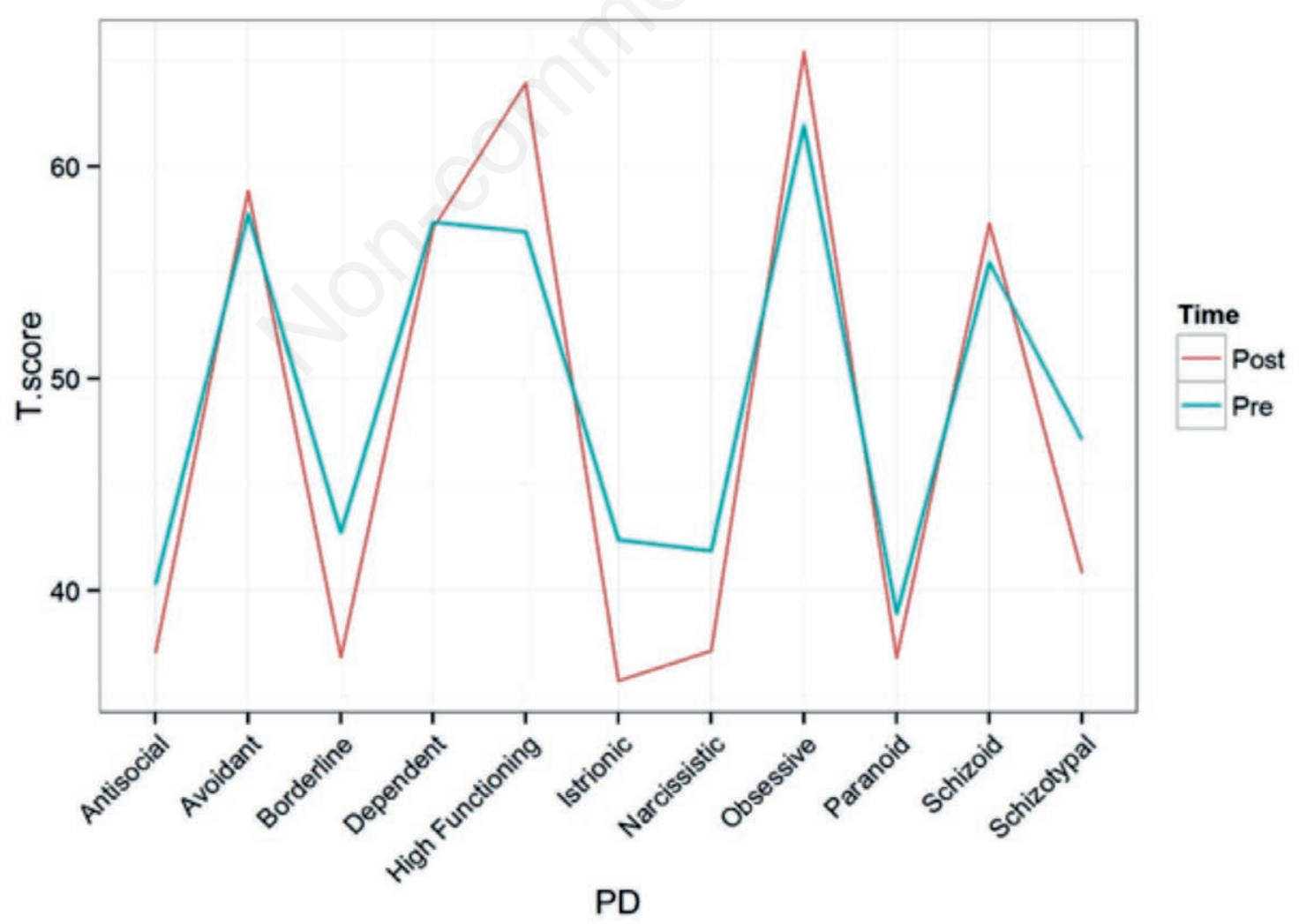

Figure 2. Shedler-Westen Assesment Procedure-200 trend. 
such frequent rupture episode was expressed when the patient was activating a particular pattern of defense mechanisms, composed by intellectualization, isolation and retroactive annulment. Another significant positive relationship was found between the Denial rupture marker and the denial defenses. Indeed, when Sara rejected passively therapist's interventions, she activated a specific pattern of defenses mechanisms composed by rationalization, neurotic denial and projection. Furthermore, results showed a positive co-occurrence between self criticism-hopelessness rupture marker and Narcissistic defenses, especially with the devaluation of Self, suggesting that Sara's ruptures were characterized by a worrying sense of impotence and powerlessness.

Critically, the co-occurrence pattern of CCRT and DMRS items indicated that relational episodes narrated by the patient were negatively associated with high-level defenses, likely reflecting a patient's non-sincere exploration of her feelings. Conversely, response of self components were positively associated with acting defenses, in particular with the passive-aggression defense. These results suggest that vague narrations of her inner feelings may convey negative emotions by means of passive-aggressive defenses.

Finally, the results of outcome evaluation corroborated the hypothesis that deferential behavior and acquiescent approach to therapist could be linked to an impasse in the treatment. In fact, Sara's emotional avoidance did not allow her to express any bad feeling about the therapist. This functioning is associated to the outcome of the therapy, obstructing a real change in her personality structure and a significant improvement in her symptomatic dimension.

In interpreting the present findings, various limitations need to be considered, especially with respect to the use of CCRT. For instance, Luborsky and Crits-Christoph (1998) suggested that valid CCRT data should rely on at least 10 relational episodes per session, whereas in the present study the number of such episodes was definitely lower. This may therefore partially limit the conclusions inferred by the CCRT results. Moreover, it is worth noting that in the present study the CCRT measure was based on a randomized selection of the sessions, to better understand the typical transference pattern in time. Yet, this criterion may as well represent a possible limitation, since CCRT evaluation on pairs of consecutive sessions typically produces more reliable measures (Luborsky \& Crits-Christoph, 1998). Although the CCRT method has been already used in sequential analyses (e.g. Chance, 2000), it was not originally proposed for a within-session analysis of the components. Therefore, despite being informative, the method used in this study needs to be substantiated by further research. More generally, the present study focused exclusively on the patient contribution to the psychotherapy process. Future studies may thus better understand outcome results by measuring the therapist involvement in the ruptures-resolution process, as well (Jørgensen, 2004). Future researches should also explore the role of deferential behavior, by possibly assessing its influence on therapeutic techniques, countertransference and therapist-patients relationship. Integrating these variables into an intersubjective approach may lead to a deeper comprehension of the psychotherapy process and outcome (Lingiardi, Holmqvist \& Safran, 2016).

Despite the aforementioned limitations, the present study provides also some stimulating suggestions for the clinical practice. Beyond unveiling the impact of deferential behavior on psychotherapy process and outcome, indeed, our findings draw new attention to the need of a proper assessment of this elusive behavioral functioning for both clinical and research purposes (Colli \& Lingiardi, 2009). In fact, deferential patients may be often treated as high functioning level patients, with the consequence of underestimating patient's resistance to therapeutic changing. Another important aspect for clinical work with deferential patients, emerged by the present study, is the key role of alliance in psychotherapy process. Results, in fact, showed that this kind of patients may maintain a collaborative alliance with the therapist, albeit at the same time, they may also convey some resistance and impasse to the therapy process, beyond the apparent collaboration. This suggests that specific techniques and therapeutic models focused on work of alliance and ruptures/resolution process may be more effective for these kinds of patients (Safran \& Kraus, 2014).

Table 4. Personality health index.

\begin{tabular}{llll}
\hline PHI scores by RADIO domains & Early & Late & Change in percentile rank (\%) \\
\hline Overall PHI & 19 & 39 & +20 \\
\hline Reality orientation & 20 & 45 & +25 \\
\hline Affect regulation & 13 & 33 & +20 \\
\hline Defenses & 23 & 32 & +9 \\
\hline Identity integration & 36 & 59 & +23 \\
\hline Object relations & 24 & 42 & +18
\end{tabular}

PHI, personality health index; RADIO, regulation and tolerance, defensive organization, identity integration, and object relations. 
Table 5. Verbatim transcripts.

\section{Defensive structure}

P: Ahah. Yes! It's been a great summer!

T: Uh.

P: Yes, indeed...

$\mathrm{T}$ (ironically): Ha ha, how dared you?

P: Yes, sure!

T (laughing): You know you can't do that!

P: It has started in the worst way, not feeling bad but with a huge sense of sadness, in the ten days I've been at sea with my mother... instead one.. doing.. we were at the seaside, with my mother, mmm... home, breakfast, beach, newspaper, what do you want for lunch?... I have done nothing at all, it's been sad! But I felt ok, I was not like I am a loser because I'm here with you, what I th.. well, what I wished going away... like thing I will do. They will be done for me!

T: Sure!

P: Not suffered passively. And we have been ok, so she..mm.. we've been ok, never nervous, there were not bad moments.. I didn't forced myself being good...having patience..

T: Yes.

P: Because I was so relaxed, without living anything exciting but we were ok, doing things that we usually like to do.

\section{Deferential and appeasing rupture}

T: There are accidents that happen during life...like that car crash happened to my brother, and in life accidents happen. No one can prevent and beat all those bad.

$\mathrm{P}$ (sighed and start laughing): Yes, you are right!

T: But there are also lucky things (laughing) otherwise a person can lose it, you know?, someone says < oh, what a terrible thing happened to me! $>$ and then he forget the other side: what a terrible thing but also what a lucky strike, because ahead he had no one, the other driver saw him in his review mirror, he was sort of prepared, had straight wheels...

P (laughing) Yes, yes, it's true!

T: If you have a selective attention considering all data, you may lose a part of the entire sequence!

P: Yes, you are right!

T: Same thing happened to you with, I think, Tommaso. In case you forget to consider the part in which you two were good together and having a good relationship, which kept on working. You were not able to consider the lucky strike of ending your love story without anger or regrets before you could begin living together. It could go very worse...

P: Exactly, sure!

T: Do you understand? Instead, again, you had lost a part of the sequence, saying what a terrible thing and not considering that it could go very, very worse...

P: You are definitely right!

$\mathrm{T}$ : And you could not say at least I have got a friend more.

$\mathrm{P}$ (laughing): It is true (pause) yes, I keep on losing parts...

T: Yes, yes. Because you have this idea of unluckiness, you know, which is very worse than it can appear (Patient laughs). You have the idea that you suffer for an unlucky faith which keeps on persecuting you and you can't do nothing to control it.

P: Yes... yes, you are terribly right.

To be continued on next page

\section{Conclusions}

In this single-case study we investigated the influence of patient's deferential behavior on psychotherapy process and outcome. We found that deferential behavior modulated the dimension of therapeutic alliance, leading the patient to build a sort of pseudo-alliance with the therapist. This pseudo-alliance was characterized by an impossibility to express any bad emotion against treatment's activities, which in turn also likely determined an impasse in the progression of the therapy. In the described dynamic, Sara adopted withdrawal ruptures and, hence, an implicit, unexpressed and non-verbalized alliance modality. In such moments, specific patterns of both mature and immature defenses were activated to avoid therapist's explorative questions. Furthermore, relational episodes nar- rated during the treatment were extremely vague and schematic and often co-occurred with avoidant defense mechanisms. This reflects the patient's core conflictual relationship theme, which was vague and ambiguous. Together, these factors contributed to the creation of an extremely rigid therapeutic context, in which the treatment was disrupted by implicit and unexpressed bad feelings. Indeed, Sara's avoidance played a double role in the treatment: on the one hand it was the main characteristic of her transference structure, based on extreme intellectualization and emotional closure. On the other hand, it contributed to create the impasse in the treatment, based on a withdrawal ruptures model and on obsessive level defenses. Therefore, Sara's alliance ruptures seem to have both transference and defensive meaning, responsible for her relational detachment and emotional constriction. 
Table 5. Continued from previous page.

Minimal response rupture

P: Yes, yes! No, It not seem...I do not think so, I don't know, I've got thins idea of... like I have to intervene in first person...

T: Wait... why you have to intervene?

P: Because yes...

T: You know...If someone asks me for a red pen, I will give to him. Then I do not remain there watching him using my pen and asking myself what can I do now for him?

$\mathrm{P}: \mathrm{Mh} .$.

T: ...It means that I'm perceiving something and I am trying to control, to manage it... I feel you continuing I should say something to you, I should say something to you, I should say something to you, like you have a sort of terrible agitation, instead of saying this situation does not work, we have to work it out.

P: Yep, $\mathrm{mh} . .$.

T: Do you understand? Worrying is that kind of rubbish, it has nothing in common with real preoccupation about the things... about the act itself, but with a sort of illusion of management of the bad situation.

P: Mmh...

Patient's typical relational episode (1)

P: You always think oh, God, what a terrible thing will happen!, but thinking it before analyzing all the data!

T: Mmm.

P: Yesterday morning, I had to write a letter together with another colleague: I was worrying, anxious, even before we began...with another colleague in the study. Then it came an e-mail of this colleague: he already wrote the letter and asked me to correct it. He neither asked something about it...but

T: Mmm.

P: Well, I'm frightened of everything happens to me...this morning a client called me carrying out a problem, which we all know it would be emerged sooner or later...like it was my fault!

T: Eeeh.

P: I was more frightened than him! Laughs I do not know...

T: It's like you always have something to repair...to resolve...Mmm.

P: Like I always have to fix everything I...I can not say it...I have to repair someone else's problem: If I can help you ok, it's fine... but If not I think myself as a loser, my situation becomes unrepairable.

Patient's typical relational episode (2)

P: Well my mother, thinking about it, she caught me in all my moments of sadness and anxiety. Me, by myself, I try not to tell her what I suffer from. I always try to...

T: To protect her...

P: Yes... because if I tell her something it's like she destabilizes me... She says Fra, let we think how it might have gone... and this annoys me because when I told her about, for example, the end of the story with my boyfriend, she was sad like everybody: she knew him, felt good together, we all hoped in another possible future... She never tried to push me doing something concrete. Even in the most uncertain moments... she told me try to realize what you want and do that but at the same time why would you let all this time pass by? Why you never tell him what was going wrong?. I hate when she carried out negative data, even when they are true. So I say if I'm not ok, well, you should...you can stay here with me but, for fuck sake, mind your fucking own business. (Laughs).

\section{References}

American Psychiatric Association (1994). Diagnostic and statistical manual of mental disorders (DSM). Washington, DC: American Psychiatric Association Publ.

American Psychiatric Association (2013). Diagnostic and statistical manual of mental disorders (DSM-V). Washington, DC: American Psychiatric Association Publ.

Bakeman, R., \& Quera, V. (2011). Sequential analysis and observational methods for the behavioral sciences. New York: Cambridge University Press.

Barber, J.P., Luborsky, L., Crits-Christoph, P., \& Diguer, L. (1998). Stability of the CCRT from before psychotherapy starts to the early sessions. In: L. Luborsky, \& P. CritsChristoph (Eds.), Understanding transference: the core conflictual relationship theme method (pp. 253-260). New York: Basic Books.
Bibring, J.L. (1937). On the theory of the results in psychoanalysis. International Journal of Psychoanalysis, 18, 170-189.

Blagov, P.S., Bi, W., Shedler, J., \& Westen, D. (2012). The Shedler-Westen Assessment Procedure (SWAP): evaluating psychometric questions about its reliability, validity, and impact of its fixed score distribution. Assessment, 19, 370-382.

Bordin, E.S. (1975). The working alliance: basis for a general theory of psychotherapy. Washington, DC: Society for Psychotherapy Research.

Borkovec, T.D., Ray, W.J., \& Stober, J. (1998). Worry: a cognitive phenomenon intimately linked to affective, physiological, and interpersonal behavioral processes. Cognitive Therapy and Research, 22, 561-576.

Brenner, C. (1979). Working alliance, therapeutic alliance and transference. Journal of American Psychoanalytic Association, 27, 136-158.

Brown, P., \& Levinson, S. (1987). Politeness: some universals in language usage. Cambridge: Cambridge University Press. 
Chance, S.E. (2000). Core conflictual relationship themes in patients diagnosed with borderline personality disorder who attempted, or who did not attempt, suicide. Psychotherapy Research, 10(3), 337-355.

Colli, A., \& Lingiardi V. (2009). The collaborative interactions scale: a new transcript-based method for the assessment of therapeutic alliance ruptures and resolutions in psychotherapy. Psychotherapy Research, 19, 718-734.

Coutinho, J., Ribeiro, E., Sousa, I., \& Safran, J.D. (2014). Comparing two methods of identifying alliance rupture events. Psychotherapy, 51,434-442.

Curtis, H.C. (1979). The concept of therapeutic alliance: implication for the widening of scope. Journal of the American Psychoanalytic Association, 27, 159-192.

Eubanks-Carter, C., Muran, J.C., \& Safran, J.D. (2015). Alliance-focused training. Psychotherapy, 52, 169-173.

Exner, J.E. (1993). The Rorschach: a comprehensive system: Vol.1. Basic foundations (3rd. ed.). New York: Wiley.

Foucault, M. (1963). Naissance de la clinique. Paris: PUF.

Freud, S. (1905). Three essays on sexuality. London: Hogarth Press.

Freud, S. (1912). The dynamics of transference. London: Hogarth Press.

Goffman, E. (1961). Asylums: essays on the social situation of mental patients and other inmates. New York: Anchor Books.

Greenacre, P. (1968). The psychoanalytic process, transference, and acting out. The International Journal of Psychoanalysis, 49, 211-218.

Greenson, R.R. (1967). The technique and practice of psychoanalysis. New York: International University Press.

Guldberg, C.A., Høglend, P., \& Perry, J.C. (1993). Scientific methods for assessing psychological defences. Nordic Journal of Psychiatry, 47, 435-446.

Henry, W.P., Schacht, T.E., \& Strupp, H.H. (1986). Structural analysis of social behavior: application to a study of interpersonal process indifferential psychotherapeutic outcome. Journal of Consulting and Clinical Psychology, 54, 27-31.

Hill, C.E., Nutt-Williams, E., Heaton, K.J., Thompson, B.J., \& Rhodes, R.H. (1996). Therapist retrospective recall impasses in long term psychotherapy. Journal of Counseling Psychology, 43(2), 207-217.

Jacobson, N.S. \& Truax, P. (1991). Clinical significance: a statistical approach to defining meaningful change in psychotherapy research. Journal of Consulting and Clinical Psychology, 59, 12-19.

Jørgensen, C.R. (2004). Active ingredients in individual psychotherapy: searching for common factors. Psychoanalytic Psychology, 21, 516-540.

Lacan, J. (1955). The Freudian thing. In: J. Lacan (Ed.) Écrits: a selection (pp. 107-137). New York, NY: Norton.

Levy, K.N., \& Scala, J.W. (2012). Transference, transference interpretations, and transference-focused psychotherapies. Psychotherapy, 49, 391-403.

Lingiardi, V. (2002). L'alleanza terapeutica. Milan: Raffaello Cortina.

Lingiardi, V., Holmqvist, R., \& Safran, J.D. (2016). Relational turn and psychotherapy research. Contemporary Psychoanalysis, 52(2), 1-38.

Luborsky, L., \& Crits-Christoph, P. (1998). Understanding transference: the core conflictual relationship theme method. Washington, DC: American Psychological Association.

Luborsky, L., Crits-Christoph, P, \& Alexander, K. (1990). Repressive style and relationship patterns: three samples inspected.
In: J. Singer (Ed.), Repression and disassociation: implications for personality theory, psychopathology and health (pp. 275-298). Chicago, IL: University of Chicago Press.

Luborsky, L., \& Diguer, L. (1998). The reliability of the CCRT measure: results from eight samples. In: L. Luborsky, \& P. Crits-Christoph (Eds.), Understanding transference: the core conflictual relationship theme method (pp. 97-108). New York, NY: Basic Books.

Marin-Avellan, L.E., McGauley, G., Campbell, C., \& Fonagy, P. (2005). Using the SWAP-200 in a personality-disordered forensic population: is it valid, reliable and useful? Journal of Criminal Behaviour and Mental Health, 15, 28-45.

Mead, H.M. (1934). Mind, self, and society. Chicago, IL: University of Chicago Press.

Meissner, W.W. (1996). The therapeutic alliance. New Haven, CT: Yale University Press.

Nunberg, H. (1928), Problems of therapy. In: H. Nunberg, (1948), Practice and theory of psychoanalysis, vol. 6. New York, NY: International Universities Press.

Perry, J.C. (1990). Defense mechanism rating scales. Cambridge, MA: Cambridge Hospital, Harvard Medical School.

Perry, J.C. (2001). A pilot study of defenses in adults with personality disorders. Journal of Nervous and Mental Disease, $10,651-660$.

Perry J.C. \& Henry, M. (2004). Studying defense mechanisms in psychotherapy using the defense mechanism rating scales. In: U. Hentschel, G. Smith, J. Draguns, \& W. Ehlers (Eds.), Defense mechanisms: theoretical, research and clinical perspectives (pp. 165-192). Amsterdam: Elsevier.

Rennie, D.L. (1992). Qualitative analysis of the client's experience of psychotherapy: the unfolding of reflexivity. In: S. Toukmanian, \& D. Rennie (Eds.) Psychotherapy process research: paradigmatic and narrative approaches (pp. 211233). Newbury Park, CA: Sage.

Rennie, D.L. (1994). Clients deference in psychotherapy. Journal of Counseling Psychology, 41, 427-437.

Rhodes, R.H., Hill, C.E., Thompson, B.J., \& Elliott, R. (1994). Client retrospective recall of resolved and unresolved misunderstanding events. Journal of Counseling Psychology, 41, 473-483.

Russell, R.L., \& Trull, T.J. (1986). Sequential analyses of language variables in psychotherapy process research. Journal of Consulting and Clinical Psychology, 54, 16-21.

Safran, J.D., \& Greenberg, L.S. (1987). Affect and the unconscious: a cognitive perspective. In: R. Stern (Ed.) Theories of the unconscious and theories of the self (pp. 145-169). Hillsdale, NJ: Analytic Press.

Safran, J.D., \& Kraus, J. (2014). Alliance ruptures, impasses, and enactments: a relational perspective. Psychotherapy, 51, 381-387.

Safran, J.D., \& Muran, J.C. (1995). Resolving therapeutic alliance rupture: diversity and integration. Psychotherapy in Practice, 1, 81-92.

Safran, J.D., Muran, J.C. (1996). The resolution of rupture in therapeutic alliance. Journal of Consulting and Clinical Psychology, 64, 447-458.

Safran, J.D., \& Muran, J.C. (2000). Negotiating the therapeutic alliance: a relational treatment guide. New York, NY: Guilford Press.

Safran, J.D., \& Muran, J.C. (2006). Has the concept of the therapeutic alliance outlived its usefulness? Psychotherapy: Theory, Research, Practice, Training, 43, 286-291. 
Safran, J.D., Muran, J.C., \& Eubanks-Carter, C. (2011). Repairing alliance ruptures. Psychotherapy, 48, 80-87.

Safran, J.D., Muran, J.C., \& Samstag, L.W. (1994). Resolving therapeutic alliance ruptures: a task analytic investigation. In A.O. Horvath, \& L.S. Greenberg (Eds.) The working alliance: theory, research and practice (pp. 225-255). New York, NY: John Wiley \& Sons.

Safran, J.D., Muran, J.C., Samstag, L.W., \& Winston, A. (2005). Evaluating alliance-focused intervention for potential treatment failures: a feasibility study and descriptive analysis. Psychotherapy: Theory, Research, Practice, Training, 42, 532-545.

Safran, J.D., Muran, J.C., \& Shaker, A. (2014). Research on therapeutic impasses and ruptures in the therapeutic alliance. Contemporary Psychoanalysis, 50, 211-232.

Sassaroli, S., \& Ruggiero, G.M. (2003). La psicopatologia cognitiva del rimuginio (worry). Psicoterapia Cognitiva e Comportamentale, 9, 31-46.

Skodol, A.E., \& Perry, J.C. (1993). Should an axis for defense mechanisms be included in DSM-IV? Comprehensive Psychiatry, 34, 108-119.

Sterba, R. (1934), The fate of the Ego in analytic therapy. The International Journal of Psychoanalysis, 115, 117-126.

Wechsler, D. (1981). Wechsler adult intelligent scale-revised manual. New York, NY: the Psychological Corporation.

Westen, D., \& Muderrisoglu, S. (2003). Reliability and validity of personality disorder assessment using a systematic clinical interview: evaluating an alternative to structured interviews. Journal of Personality Disorders, 17, 350-368.

Westen, D. \& Shedler, J. (1999). Revising and assessing Axis II: I. Developing a clinically and empirically valid assessment method. American Journal of Psychiatry, 156, 258-272.

Westen, D., \& Shedler, J. (2007). Personality diagnosis with the Shedler-Westen Assessment Procedure (SWAP): integrating clinical and statistical measurement and prediction. Journal of Abnormal Psychology, 116, 810-822.

Zetzel E.R. (1956). Current concepts of transference. International Journal of Psychoanalysis, 37, 369-375. 